\title{
Ccnnll Prophylaxis of venous thromboembolism in knee replacement surgery
}

\author{
Carlo Rostagno ${ }^{1}$, Christian Carulli ${ }^{2}$, Alessandro Cartei $^{1}$, Claudia Ranalli ${ }^{1}$, \\ Massimo Curcio ${ }^{1}$, Alessandra Cammilli ${ }^{1}$, Gian Luca Polidori ${ }^{1}$, \\ Massimo Innocenti
}

'SOD Medicina Interna e postchirurgica AOU Careggi, Firenze, Italy.

${ }^{2} \mathrm{SOD}$ Ortopedia e traumatologia AOU Careggi, Firenze, Italy

Address for correspondence: Carlo Rostagno,

SOD Medicina Interna e post chirurgica AOU Careggi Firenze, Italy. carlo.rostagno@unifi.it

Received: July 13, 2016

Accepted: August 29, 2016

Published: November 23, 2016

\begin{abstract}
Venous thromboembolism (VTE) is still a frequent and sometimes severe complication after knee replacement surgery. Both pharmacological and non-pharmacological measures have been widely used to decrease VTE risk. Non pharmacological treatment include measures directed to decrease the effects of blood stasis, intermittent pneumatic compression device (IPCD) and graduated compression stockings, and mechanical devices. Pharmacological prophylaxis of venous thromboembolism (VTE) is associated with a more significant decrease in the incidence of deep venous thrombosis (DVT) and related complications after knee arthroplasty however anticoagulation may increase the risk of postoperative bleeding and related complications, in particular the need for re-intervention. Aim of present review was to suggest practical approach to DVT prophylaxis in patients undergoing knee arthroplasty.

Although parenteral drugs (low dose unfractionated heparin, low molecular weight heparin and fondaparinux) are the more frequently employed agents, limited compliance may be a concern. Recent studies suggest that direct oral anticoagulants, antithrombin and anti Xa agent, might be a useful alternative although safety may limited by an higher rate of local bleeding.
\end{abstract}

KEY WORDS: Knee surgery; Venous thrombosis; Prophylaxis; Pulmonary embolism; Heparin; Enoxaparin; Warfarin; Dabigratan; Rivaroxaban; Fondaparinux; Doppler ultrasound

\section{INTRODUCTION}

Despite widespread use of antithrombotic prophylaxis the risk of deep venous thrombosis (DVT) after major orthopedic surgery is still not negligible [1,2]. DVT in these patients is frequently distal, asymptomatic and diagnosed only by routine ultrasonography. Usually the thrombus lyses with complete recovery. Late pulmonary embolism however has been reported even 40 days after surgery [3-5]. At present no clear indication about the need for prolonged anticoagulation in small distal DVT has been provided.

In an observational study Wang et al [6] reported that 160 out of 359 patients developed distal DVT after TKR. Eighty three $(52 \%)$ involved the gastrocnemius and soleus muscular veins: 38 (46\%) were isolated muscular DVT and 45 (54\%) involved muscular branches and major leg veins. Rates of clinical symptoms, late DVT, thrombus propagation and pulmonary embolism in patients with isolated muscular DVT were comparable between patients with isolated muscular DVT in comparison to patients with DVT in the major leg veins and patients with combined lesions [7].

The incidence of symptomatic DVT is comprised between $1.5-10 \%$ of patients undergoing knee artrhoplasty, while fatal pulmonary embolism is relatively uncommon ( 0.5 to $1.5 \%)$ $[1,8]$. These data are confirmed by a systematic review that reported an incidence of VTE of $1.09 \%$ for knee surgery ( DVT $0.63 \%$, pulmonary embolism -PE- $0.27 \%$ ) in patients in adequate drug prophylaxis [8]. A recent paper from
Waitemata District Health Board - New Zealand - reports in a 4 year period a cumulative incidence of symptomatic VTE within 90 days of surgery of 3.29\% [9]. The median time from surgery to diagnosis was 7 days. Deep vein thrombosis comprised $75 \%$ of cases, $77.6 \%$ distal and $23.2 \%$ proximal. Pulmonary embolism comprised $26.5 \%$ of VTE; 47.7\% had right heart strain on computed tomography/ echocardiography. Of patients developing VTE, 85.5\% had pharmacological thrombo prophylaxis - aspirin 73\%, LMWH $20 \mathrm{mg}$ 16\%, LMWH $40 \mathrm{mg}$ 16\%, therapeutic LMWH $3 \%$, unfractionated heparin twice daily $1 \%$, and warfarin $4 \%$; $75.6 \%$ received mechanical prophylaxis, while $4 \%$ of patients received no prophylaxis.

The main limitation of pharmacologic VTE prophylaxis is the risk of bleeding and related complications, in particular the need for re intervention. Major bleeding following TKR has been estimated between $l$ and 3 percent. These data however suffer from the limitation of the variability in the definitions of bleeding used in published literature and few data in control patients.

\section{PATHOPHYSIOLOGY}

Knee replacement surgery is associated with trauma to the soft tissues and bone with release of cytokines and other pro-coagulant factors [10]. Excessive release of tissue factor from injury to the vascular wall leads to generation of large amounts of thrombin, which favors platelet activation and thrombus formation [11]. 
Finally blood venous stasis occurs as a result of several different factors: immobilization, edema, poor calf muscle pump and mechanical haemostatic devices used in surgery room. Manipulation of the limb and the use of a tourniquet in patients undergoing TKA also contribute to venous stasis. [12]. VTE risk is highest in the first days after surgery, on average 7 days after TKA in comparison to 17 days after THA [1]. Early discontinuation of pharmacological prophylaxis favors extension of preexistent asymptomatic thrombosis or development of new thrombotic events.

The risk to develop DVT is significantly higher in patients undergoing knee replacement in comparison to both hip replacement and treatment of hip fracture [13-14] with a 4:1 ratio between distal and proximal thrombosis. Age, underlying pre-existing diseases (cancer, obesity, previous DVT, thrombophylic conditions including those genetically determined ), injury related factors and finally factors related to medical procedures significantly influence DVT risk [15].

Female sex and previous DVT were the more relevant risk factors for DVT independently from the drug used for pharmacological prophylaxis in the ORTHO-TEP study [16] . In a study by Kang et al [17] DVT was detected by B-mode ultrasonography performed 7 days after TKR in $175 / 1025$ patents aged $>75$ years. Diabetes $(\mathrm{P}=$ $0.014)$, high body mass index $(\mathrm{BMI})(\mathrm{P}=0.003)$ and hyperomocysteinemia $(\mathrm{P}<0.001)$ were significantly more frequent in the thrombus group. A significantly greater proportion of patients in the non-thrombus group had early postoperative activity $(\mathrm{P}<0.001)$ and used a foot pump $(\mathrm{P}<0.001)$. Operative duration was significantly longer in the thrombus group $(\mathrm{P}=0.012)$. DVT was more frequent in bilateral than unilateral knee arthroplasty $(\mathrm{P}<0.01)$. Multivariate logistic analysis revealed BMI, long operative duration, bilateral knee arthroplasty, and time to the activity after the operation to be predictive factors of DVT. At 6-month follow-up in DVT group, $4.7 \%$ of patients had pulmonary embolism and $18.8 \%$ had recurrent DVT.

\section{ProhPylaxis of DVT -PE}

In patients undergoing major orthopaedic surgery pharmacological and non-pharmacological measures are available for VTE prophylaxis. At present parenteral agent, low dose unfractionated heparin (UH), low molecular weight heparins (LMWH) and fondaparinux are mainly used for drug prophylaxis. Direct oral anticoagulants may be indicated in elective surgery in patients with expected poor adherence to parenteral route. Non pharmacological treatment include measures directed to decrease the effects of blood stasis, intermittent pneumatic compression device (IPCD) and graduated compression stockings, and mechanical devices, IVC filters to avoid migration of eventual emboli to pulmonary circulation. IPCD and graduated compression stockings anyway should be considered as adjunctive measures or used when contraindications exist to drug prophylaxis.

\section{Low dose unfractionated heparin}

Low dose subcutaneous unfractionated heparin (UH has been widely used for VTE prophylaxis before 1990. At present indication for low dose unfractionated heparin are limited, as clear evidence has been provided of superiority of LMWH [18]. In advanced renal failure ( creatinine clearance $<30 \mathrm{ml} / \mathrm{min}$ ) UH may instead of LMWH in order to decrease haemorrhagic risk.

\section{Low molecular weight heparin ( LMWH)}

LMWH at present are the drugs of choice for pharmacological prophylaxis of DVT in orthopaedic surgery [19-21]. After TKR treatment decreases by more than $50 \%$ the risk of post-operative asymptomatic DVT in comparison to no prophylaxis. Several studies have clearly demonstrated the superiority of LMWH in comparison to UH and adjusted dose warfarin with a similar, or superior in the case of warfarin, safety profile [22-24]. The risk for heparin induced thrombocytopenia ( HIT) is lower with LMWH than with UH [25]. Effects on symptomatic DVT or PE were not significantly different when LMWH was compared to fondaparinux, however the latter showed an higher bleeding rate leading to re-intervention [26-29].

Each LMWH has a specific molecular weight distribution that influence anticoagulant activity, duration of action, and renal clearance, so each agent must be considered a unique drug and one product cannot always be substituted for another (table 1).

Table 1. LMWHs available for DVT prophylaxis

\begin{tabular}{ll}
\hline $\begin{array}{l}\text { Active } \\
\text { principle }\end{array}$ & Standard dosage \\
\hline Dalteparin & $5.000 \mathrm{IU}$ before surgery, thereafter $5000 \mathrm{IU} /$ day \\
& $\begin{array}{l}40 \mathrm{mg}(4000 \mathrm{IU}) 12 \mathrm{~h} \text { before surgery, thereafter } \\
40 \mathrm{mg} \text { daily (european dose ). } 30 \mathrm{mg} \text { ( } 3000 \mathrm{IU}) \\
\text { before surgery, thereafter } 30 \mathrm{mg} \text { b.i.d }\end{array}$ \\
$\begin{array}{ll}38 \mathrm{IU} / \mathrm{kg} 12 \mathrm{~h} \text { before surgery and } 12 \text { hours after. } 38 \\
\text { Enoxaparin } \\
\text { Nadroparin } / \mathrm{kg} \text { for the next } 3 \text { days, then increase the dose to } \\
57 \mathrm{IU} / \mathrm{day}\end{array}$ \\
Reviparin & $4200 \mathrm{IU}$ before surgery, thereafter $4200 \mathrm{IU} /$ day \\
\hline
\end{tabular}

At present no clear evidence has been provided on the optimal dose to be employed nor regarding efficacy difference among different molecules. For enoxaparin European approved regimen is $40 \mathrm{mg}$ (4000 IU) once -daily, US regimen is 30 mg b.i.d. Dose for patients with decreased renal function must be adjusted in relation to creatinine-clearance.

Duration of treatment, initially limited to 10-14 days, after the demonstration of a non negligible risk of DVT after hospital discharge has been extended over 30 days [30].

\section{Fondaparinux}

Fondaparinux, a synthetic drug, indirectly inhibits activated factor $\mathrm{X}$ through an high affinity binding with antithrombin. Only one study examined the effects of fondaparinux in comparison to placebo [31]. Although a 
decrease of PE was reported, other end -points were not significantly affected and, due to increased bleeding risk , it was impossible to assess a beneficial effect on overall mortality. Results from 4 randomized studies comparing fondaparinux to enoxaparin were reported by Turpie et al [32]. The original primary efficacy end point consisted of a composite of deep-vein thrombosis detected by mandatory bilateral venography, documented symptomatic deep-vein thrombosis, or pulmonary embolism up to day 11 . The incidence of VTE was $13.7 \%$ (371 of 2,703 patients) in the enoxaparin group compared with 6.8\% (182 of 2,682 patients) in the fondaparinux group, with a risk reduction of $55.2 \%$ in favour of fondaparinux.

ORTHO-TEP registry compared the efficacy and safety of fondaparinux and LMWH in 3819 patients undergoing major orthopaedic surgery [16]. The main limitation of the study was its retrospective nature and the comparison of two different periods, the first in which LMWH ( 3000-6000 $\mathrm{aX} \mathrm{U}$ ) and in the second with fondaparinux $2.5 \mathrm{mg}$ used as thromboprophylaxis,. Symptomatic DVT occurred in $4.1 \%$ of patients treated with LMWH in comparison to $5.6 \%$ in patients treated with fondaparinux. No significant difference was found between the two regimens in the incidence of pulmonary embolism and death. Despite similar overall incidence of bleeding the need for surgical revision was lower with fondaparinux. At multivariate analysis previous VTE and female sex were associated with an increased risk of DTV.

\section{Vitamin $\mathrm{K}$ antagonists}

In United States adjusted dose warfarin is still used for DVT prophylaxis in orthopaedic surgery [33-34]. Extended vitamin $\mathrm{K}$ antagonists treatment ( $>4$ weeks) after THA was associated with a $4.6 \%$ absolute decrease of VTE with a small increase in the risk of bleeding [35].

\section{Aspirin}

Studies on the effects of aspirin in DVT prophylaxis failed to demonstrate a favourable effect in patients undergoing THA, TKR or finally treatment for hip fracture [36-37]. It must be emphasized that serious methodological limitations impair a correct interpretation of these studies. Raphael et al [38] analyzed retrospectively a total of 28,923 patients underwent THA or TKA between January 2000 and June 2012. Patients were treated with either aspirin $(325 \mathrm{mg}$ twice daily; 2800 patients) or warfarin (26,123 patients). The overall symptomatic PE rate was lower $(\mathrm{p}<0.001)$ in patients receiving aspirin $(0.14 \%)$ than in the patients receiving warfarin $(1.07 \%)$. This difference did not change after matching. The aspirin group also had significantly fewer symptomatic DVTs and wound-related problems. Jiang et al [39] randomized 120 patients undergoing TKA to aspirin combined with mechanical measures postoperatively (group A), and respectively low-molecularweight heparin (LMWH) sodium and rivaroxaban sequentially in combination with mechanical measures (group B). Postoperatively DVT was detected in 10 of 60 patients in group $A(16.7 \%$, ) compared with 11 of 60 in group
B (18.3\%) $(\mathrm{P}=0.500)$. There were no cases of symptomatic VTE or death during the follow-up period. Patients in group A had the lower blood loss index as compared with patients in group B. The cost of VTE prevention analysis indicated a cost reduction using aspirin in group A compared with using $\mathrm{LMWH}$ and rivaroxaban in group $\mathrm{B}$.

\section{Direct oral anticoagulants}

In the last decade several oral direct anticoagulant have been introduced in clinical practice. These agents have predictable anticoagulant effect, limited drug or food interactions and therefore may be administered at fixed doses without the need for regular laboratory monitoring and dose adjustments. Dabigatran exilate is a selective thrombin inhibitor while apixaban, rivaroxaban and edoxaban are direct Xa factor inhibitors (figure 1). These drugs differ for pharmacological and pharmacodynamics characteristics. Clinical studies, usually, have compared these drugs in TKA against enoxaparin at US or Europe dosages (respectively $3000 \mathrm{IU}-30 \mathrm{mg}$ - bi.d. and 4000 IU daily). Most published trials have a similar primary end point e.g. combined symptomatic or asymptomatic (diagnosed by venography) DVT, non fatal pulmonary embolism and all cause mortality. A higher compliance after hospital discharge has been reported in comparison to low molecular weight heparin. Potential safety concerns must to be cleared by time. Dabigatran is a substrate for efflux transporter P-gp: administration in association with a P-gp inhibitor (amiodarone, verapamil, quinidine, ketokenazole, dronedarone ) may increase intestinal absorption increasing blood levels and the risk of bleeding. Conversely P-gp inducers (rifampicin, carbamazepine and phenytoine ) may decrease plasma concentrations of dabigatran. Apixaban and rivaroxaban are substrates of CYP3A4 / 5 and P-gP transporters. Concomitant administration of inhibitors of these systems such azole antifungine, HIV protease inhibitors may lead to increase of anticoagulation. By converse inducers of these systems decrease plasma levels of apixaban and rivaroxaban. No significant increase of bleeding rate has been demonstrated with concomitant use of aspirin or NSAID in patients treated with dabigatran both at 150 and $220 \mathrm{mg}$ doses.

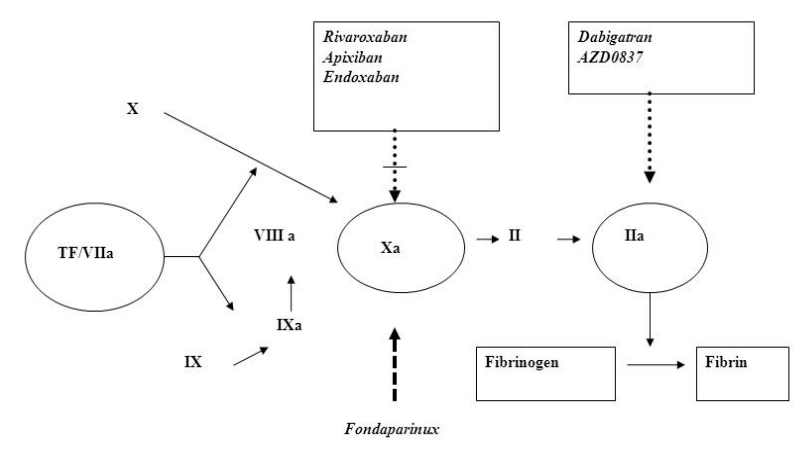

Figure 1. Mechanism of action of new anticoagulants 


\section{Anti thrombin agent}

Dabigatran etexilate is a pro-drug quickly converted in dabigatran by cytochrome P-450-independent esterases. Anticoagulant effect of dabigatran is reated to a powerful reversible direct competitive inhibitor of both free and clot included thrombin. Onset of action is prompt, it has a consistent anticoagulant effect. The half-life ranges between 12 and $17 \mathrm{~h}$ [40] but since kidney excretion accounts for $85 \%$ elimination, half-life does increase significantly also in patients with moderate renal failure ( creatinine clearance $<50 \mathrm{ml} / \mathrm{min}$ ).

Two large randomized trials compared dabigatran etexilate $75 \mathrm{mg}$ or $110 \mathrm{mg}$ within 1 to 4 hours of surgery followed by 150 or $220 \mathrm{mg}$ daily thereafter to enoxaparin $40 \mathrm{mg}$ on the day prior to surgery and daily thereafter in patients undergoing elective major orthopedic surgery. In the REMODEL trial were included 2101 patients undergoing knee replacement [41] and duration of treatment was 6 to 10 days. Exclusion criteria were haemorrhagic diathesis and sever liver or kidney failure. Administration of COX-2 inhibitors and aspirin were allowed during treatment period. Dabigatran etexilate at 150 and $220 \mathrm{mg}$ was statistically non-inferior to enoxaparin in the combined end point of symptomatic or asymptomatic (diagnosed by venography at the end of treatment period ) DVT, non fatal pulmonary embolism and all cause mortality. In RE-MODEL study symptomatic VTE occurred in $2.6 \%$ and $3.8 \%$ at dabigratran dosage of $220 \mathrm{mg}$ and respectively $150 \mathrm{mg}$ in comparison to $3.5 \%$ of enoxaparin. In REMOBILIZE study [42] dabigatran (150 or $220 \mathrm{mg}$ ) was compared to enoxaparin $(30 \mathrm{mg}$ b.i.d.) for prevention of VTE after TKR. At variance with other studies enpaxaparin was superior to dabigatran. However better results obtained with enoxaparin may be explained by the higher doses employed and by a later start of treatment with dabigatran (12 hours after surgery).

A decreased dose (150 mg daily) must be prescribed in patients aged $>75$ years or with impaired renal function (creatinine clearance between 30 and $60 \mathrm{ml} / \mathrm{min}$ ) or treated with P-glycoprotein inhibitors (verapamil, amiodarone or quinidine ).

\section{Activated $\mathrm{X}$ factor inhibitors}

Rivaroxaban is an active direct inhibitor of coagulation Factor Xa. Maximal inhibition of factor Xa occurs three hours after a dose. Although effects lasts 8-12 hours factor Xa activity does not return to normal within 24 hours so once-daily dosing is advised.

The effects of rivaroxaban in orthopedic surgery have been examined RECORD studies. In this group of trials primary composite efficacy endpoint was any DVT, nonfatal PE, or death from any cause. The RECORD 3 ( 2531 patients ) study [43] showed that rivaroxaban started postoperatively and administered for 10-14 days was significantly more effective than enoxaparin 40 $\mathrm{mg} /$ day started preoperatively in patients undergoing TKA.
The absolute risk reduction of the primary endpoint was $9.2 \%$ at two weeks in RECORD 3. Safety profiles were similar between the two drugs.

Rivaroxaban was compared with enoxaparin $30 \mathrm{mg}$ b.i.d, both started postoperatively and continued for 10-14 days in patients undergoing TKR in RECORD 4 trial [44]. Incidence of primary efficacy outcome at day 17 after surgery were respectively $6.9 \%$ and $10.1 \%$ in patients randomized to rivaroxaban or enoxaparin. After introduction of NICE guidelines administration of rivaroxaban was associated, in comparison to an historical control group, with a significant decrease of symptomatic confirmed pulmonary embolism ( $2 / 266$ vs $24 / 596, p=0.0084)$ but at the expense of a significant increase of complications at surgical site [45].

The significant decrease of total DVT and all cause mortality (HR 0.46, 95\% CI 0.39-0.54), was obtained however at the expense of a significantly higher risk of significant bleeding and a trend towards an higher risk of major bleeding ( RR 1.25 , 95\% CI 1.05-1.49). A recent retrospective study compared 369 patients receiving simultaneous combined mechanical and pharmacological thromboprophylactic modality and 385 patients receiving sequential combined modality with earlymechanical compression treatment followed by rivaroxaban 2 days later after primary total knee arthroplasty surgery [46]. The incidence rates of proximal and distal DVT tested on the 2nd postoperative day, had no significant difference in the sequential group (4.16\%) compared with those $(3.25 \%)$ in the simultaneous group. No difference was found in the incidence rate of proximal and distal DVT on the 5 th week between groups. No pulmonary embolism occurred. The mean volume of wound drainage in the sequential group was $343 \mathrm{~mL}$ which was $98 \mathrm{~mL}$ lesser than in the simultaneous group $(\mathrm{p}<0.001)$. The use of the mechanical compression method alone during the early-postoperative 48 hours, then followed by rivaroxaban then until the 5 th week had the same antithrombotic effects and reduced the postoperative wound drainage volume as compared with simultaneous combined modalities.

\section{Apixaban}

Apixaban is a reversible inhibitor of activated $\mathrm{X}$ factor. Apixiban half life is close to 12 hours. The drug is cleared through hepatic and renal route, the last contributing for $27 \%$. Daily dosage is $2.5 \mathrm{mg}$ b.i.d. The effects of apixiban in major orthopedic surgery were examined by the ADVANCE trials. In ADVANCE 1 apixaban $2.5 \mathrm{mg}$ b.i.d. was compared to enoxaparin $(30 \mathrm{mg}$ every 12 hours started after surgery) in 3195 patients undergoing TKA [47]. Treatment were administered for 10-14 days. Primary end point (symptomatic or asymptomatic DVT, non fatal EP and overall mortality) was reached in $9 \%$ of apixiban group in comparison to $8.8 \%$ in enoxaparin group. Bleeding was less frequent with apixiban than with enoxaparin $-0,7 \%$ vs. $1.4 \%-(\mathrm{P}=0.053)$.

ADVANCE 2 trial (3057 patients) compared apixaban with enoxaparin in patients undergoing TKA. Primary efficacy 
outcome incidence was $15.1 \%$ in the apixaban group and $24.4 \%$ in the enoxaparin group (relative risk 0.62, 95\% CI 0.51-0.74) [48]. In apixaban group proximal DVT, symptomatic nonfatal PE, and VTE-related death occurred in $1.1 \%$ of patients vs. $2.2 \%$ of those given enoxaparin (relative risk $0.50,95 \%$ CI 0.26-0.97). The incidence of bleeding was lower with apixaban in comparison to enoxaparin $(\mathrm{P}=0.09)$

A metanalysis of the ADVANCE studies showed that apixaban (2.5 mg b.i,d,) compared to enoxaparin significantly decreased total DVT and all cause mortality (HR $0.46,95 \%$ CI $0.39-0.54)$. However the risk of symptomatic VTE was not significantly different (RR $0.81,95 \%$ CI 0.41 $1.66, \mathrm{p}=0.57)$. Otherwise the administration enoxaparin was associated with an higher incidence of bleeding requiring reoperation. The reported lower risk of major bleeding and significant bleeding reported for apixaban is limited by the fact that drop in haemoglobin was not calculated in comparison to baseline values but on immediate postoperative haemoglobin, thus effective bleeding effects may be underestimated.

\section{Edoxaban}

Limited experience has been provided with edoxaban in elective orthopaedic surgery. STARS E-3 compared edoxaban ( $30 \mathrm{mg}$ once daily started 6-24 hours after surgery ) wit enoxaparin $20 \mathrm{mg}$ b.i,d, in 746 patients undergoing TKA [49] In STARS E-3 edoxaban decreased DVT in comparison to enoxaparin ( 2.4 vs $6.9 \%$ ). Bleeding rate did not differ between the two drugs. Recently were published data about 300 patients undergoing TKA treated with edoxaban 15 $\mathrm{mg}$, enoxaparin $20 \mathrm{mg}$ b.i.d and fondaparinux $1.5 \mathrm{mg}$ once a day for a period of 14 days [50 ]. Edoxaban resulted more efficient in comparison to the other two prophylaxis regimens. A randomized study evaluated the effectiveness of a A-V Impulse System foot pump associated with edoxaban in the prophylaxis of DVT after TKA [51]. The authors did not find any significant difference in primary outcomes (any DVT as detected by bilateral ultrasonography up to postoperative day 10 and pulmonary embolism PE up to postoperative day 28 ) and safety outcomes ( bleeding and death of any cause up to postoperative day 28).

\section{Management of bleeding}

Specific antidotes for NAO are in development and idarucizumab, a drug-specific antidote targeted to reverse the direct thrombin inhibitor dabigatran has been demonstrated efficacy and safe in animal models [52] and in healthy volunteers [53]. Idarucizumab administration is associated with immediate, complete, and sustained reversal of dabigatran-induced anticoagulation in healthy men, and was well tolerated with no unexpected or clinically relevant safety concerns. Andexanet alfa is a class-specific antidote targeted to reverse the oral direct factor Xa inhibitors as well as the indirect inhibitor, enoxaparin. Ciraparantag is a universal antidote targeted to reverse the direct thrombin and factor Xa inhibitors as well as the indirect inhibitor, enoxaparin. At present, waiting clinical introduction of drug antidotes, the management of bleeding should be guided by location and severity of haemorrhage. Drug discontinuation and local compression, when possible, should be immediately adopted to stop bleeding. In case of minor bleeding (haematuria or epistaxis) resuming drug after resolution of bleeding may be sufficient. In patients with major bleeding maintaining diuresis, administration of charcoal, transfusion of red blood cells and fresh frozen plasma may be used. Limited evidence exist that prothrombin complex concentrates, activated prothrombin complex concentrates (FEIBA) and rVIIa factor, may contribute to reversing the anticoagulant effects of Xa factor inhibitors in patients with severe hemorrhagic complications.

\section{TIMING OF DRUG ADMINISTRATION FOR THROMBOPROPHYLAXIS}

Timing of the first dose of anticoagulants in patients undergoing TKR has not still clearly defined. In TKR perioperative thromboprophylaxis, 2 hours before till to 6 hours after surgery, has been associated with increase of bleeding risk [54]. Late treatment, beyond 12 hours, otherwise seems to be associated with an higher VTE risk.

\section{COMPARISON OF DIFFERENT METHODS}

Few studies compared the efficacy and safety of different antithrombotic methods and/ or agents on venous thromboembolism (VTE) after unilateral total knee arthroplasty. A recent study from China showed that aspirin, low-molecular-weight heparin, and rivaroxaban could effectively reduce the incidence of VTE after total knee arthroplasty, and their efficacy was similar [55]. Rivaroxaban however had a higher incidence of bleeding complication suggesting again some concerns on its safety.

Bern et al [56] randomized 355 patients in three groups A: variable dose warfarin (first dose on the night preceding surgery with subsequent target INR 2.0-2.5), B: $2.5 \mathrm{mg}$ fondaparinux daily starting 6-18 h postoperatively, or C: fixed $1.0 \mathrm{mg}$ dose warfarin daily starting 7 days preoperatively. All treatments continued until bilateral leg venous ultrasound day $28 \pm 2$ or earlier upon a VTE event. Two patients in Arm $\mathrm{C}$ had asymptomatic distal DVT. One major bleed occurred in Arm B and one in Arm C (ischemic colitis). Fixed low dose warfarin started preoperatively was equivalent to two other standards of care under study (95\% CI: - $0.0428,0.0067$ for both) as VTE prophylaxis.

A metaanalysis of three studies involving 11,659 patients, the risk of symptomatic DVT (pooled OR $0.38,95 \%$ CI $0.16-0.90,, \mathrm{p}=0.03$ ) and bleeding (pooled OR $0.87,95 \% \mathrm{CI}$ $0.77-0.99, \mathrm{p}=0.03$ ) was less in apixaban group compared to the enoxaparin group [57]. However, it was interesting to note that on subgroup analysis, the risk of $\mathrm{PE}$ was higher with apixaban when used for thromboprophylaxis in knee replacement surgery (pooled OR 2.58, 95\% CI 1.10-6.04, $\mathrm{p}=0.03)$. 


\section{VTE PROPHYLAXIS IN TKR IN HAEMOPHILIA}

A debated point is the need of a VTE prophylaxis in patients affected by Haemophilia undergoing orthopaedic surgery [58].

Haemophilia is a X-linked disease characterized by an inherited lack of coagulative factors as factor VIII or IX associated with a high risk of haemorrhages. Due to the recent improvements in the prevention of bleedings by primary or secondary haematologic prophylaxis, the most frequent complication of Haemophilia is the haemophilic arthropathy in specific joints, called "target joints" [59]. The most involved joint is the knee, and often the quality of life is poor due to the severity of symptoms and functional impairment: conservative treatments and minimally invasive procedures are rarely useful in such cases [60-61]. In the recent decades a high increase of the TKA performed in such patients has been recorded, given the fact that major surgery is the only procedure that may induce adequate pain relief and functional recovery [62-63].

VTE is a recognized complication after joint replacement surgery, and a prophylaxis is routinely used in patients without bleeding disorders. However, in haemophilic patients, the pharmacologic VTE prophylaxis is highly variable and controversial because of the inherent bleeding risk.

A recent review regarding 71 hip or knee replacements in 42 consecutive patients affected by Haemophilia A or B was compared to the literature in order to ascertain the incidence of VTE after THA and TKA in the haemophilic population [58]. In all patients compression stockings were applied up to 6 weeks after surgery; additionally, in 6 cases $(10.5 \%)$ sequential intermittent compression devices were used, and $2(2.8 \%)$ received a postoperative low-molecular-weight heparin (LMWH) regimen. One patient (1.4\%) receiving LMWH had a symptomatic VTE ten days after the hip replacement for a traumatic proximal femur fracture. None of the remainders (70 patients) reported any symptomatic VTE within 3 months after surgery. An estimated incidence of symptomatic VTE of $0.5 \%$ was assessed from the analysis of pooled data from several series of haemophilic patients undergoing a joint replacement. The conclusion was that in patients with Haemophilia, joint replacements can be safely performed without a routinary VTE prophylaxis, and without an increasing risk of thromboembolic events [58].

Another retrospective study on 38 cases of TKA in 33 haemophilic patients was reported to evaluate any case of DVT pre- and postoperatively by US. No patients performed a DVT prophylaxis. Also D-dimer and fibrinogen degradation product were measured before and after surgery. No case of DVT was found in either pre- or postoperative examinations [64].

This approach has been safely adopted in many series and not only for knee surgery, but also for other major procedures, as Total Hip Arthroplasty (THA) [65].

Peculiar conditions in which a VTE prophylaxis may be not indicated is the presence of inhibitors, antibodies against recombinant factors developed by some patients, able to limit the efficacy of clotting factors [66-67]. In such patients, the high risk of bleeding is more consistent than the risk of VTE. However, the high doses of bypassing agents (recombinant factor VII) used to activate the coagulative cascade may induce a variable risk requiring a strict and multidisciplinary daily evaluation in dedicated centres by tailored administration protocols.

To reduce the risk of VTE in inhibitor patients undergoing major orthopaedic surgery, the use of non-pharmacologic measures, such as standard compression stockings, mechanical prophylaxis, and early functional recovery seem to be appropriate.

\section{CONCLUSIONS}

The synthesis of recommendation for VTE prophylaxis in knee replacement has been provided by guidelines produced in the recent past years by international scientific societies [66-67]. The American college of Chest Physicians antithrombotic and prevention of thrombosis guidelines [69] suggests that in patients undergoing TKA the administration of LMWH, fondaparinux , apixaban , dabigatran , rivaroxaban , LDUH, adjusted dose warfarin of finally aspirin has grade 1 $\mathrm{B}$ recommendation, while intermittent compression devices (ICPD) has a grade lc recommendation. The use of LMWH (with or without ICPD) is preferred to other drugs with a grade $2 \mathrm{~B}$ recommendation. LMWH should be preferred to other agents in patients at high risk of bleeding. Since a nonadherence rate between 13 and $27 \%$ has been demonstrated in patients treated with LMWH or fondaparinux. direct oral anticoagulants should be considered in patients with expected poor adherence to parenteral route of administration. The treatments should be started either 12 or more hours before surgery or 12 hours or more after. Combination of pharmacological prophylaxis and ICPD for at least $18 \mathrm{~h} /$ day has a grade $2 \mathrm{C}$ recommendation. ICPD alone may be considered for patients at high risk of bleeding. IVC filters are not recommended for prophylaxis of thromboembolism in patients undergoing major orthopaedic surgery, even in the case of high risk of bleeding or contraindication to mechanical prophylaxis. American Academy of Orthopedic Surgeons (AAOS) guidelines for the prevention of venous thromboembolism (VTE) in patients undergoing hip or knee surgery [67] evaluate the efficacy of various agents in preventing pulmonary embolus rejecting asymptomatic DVT as end point. The AAOS guidelines accept the use of aspirin combined with mechanical compression devices, and low-dose warfarin therapy. These guidelines in synthesis express a major concern with the risks associated with anticoagulation therapy. However as expressed by ACCP guidelines randomized data clearly demonstrated a decrease of both DVT and PE by thromboprophylaxis. Moreover the AAOS recommended routine preoperative assessment for risk of $\mathrm{PE}$ and bleeding and stratified their recommendations for thromboprophylaxis according to whether patients are "standard risk" or "high risk" for PE and bleeding. They did 
not discuss the issue of dose adjustments in the elderly or those with renal dysfunction, which are the most important indicators of high bleeding risk.

Low molecular weight heparin at European dosage (4000 IU) started before surgery is the usual regimen adopted in elective knee arthroplasty in our clinical practice while direct oral anticoagulants are prescribed in selected cases with expected poor compliance to parenteral agents.

\section{CONFLICT OF INTEREST}

The authors declare that they have no conflict of interest

\section{LIST OF ABBREVIATIONS :}

DVT $=$ deep venous thrombosis

THA $=$ total hip arthroplasty

TKA $=$ total knee arthroplasty

LMWH = low molecular weight heparin

$\mathrm{UH}=\mathrm{un}$ fractionated heparin

PTS $=$ post thrombotic syndrome

\section{REFERENCES}

1. Cohen AT, Agnelli G, Anderson FA, Arcelus JI, Bergqvist D, Brecht JG, Greer IA, Heit JA, Hutchinson JL, Kakkar AK, Mottier D, Oger E, Samama MM, Spannagl M. VTE Impact Assessment Group in Europe (VITAE). Venous thromboembolism (VTE) in Europe. The number of VTE events and associated morbidity and mortality. Thromb. Haemost. 2007; 98(4):756-64.

2. Kroegel C, Reissig A. Principle mechanisms underlying venous thromboembolism: epidemiology, risk factors, pathophysiology and pathogenesis. Respiration 2003;70:7-30.

3. Anand S, Buch, K. Post-discharge symptomatic thromboembolic events in hip fracture patients Ann R Coll Surg of Engl 2007; 89:517-20

4. Kakkar AK, Brenner B, Dahl OE, Eriksson BI, Mouret P, Muntz J, Soglian AG, Pap AF, Misselwitz F, Haas S. RECORD2 Investigators. Extended duration rivaroxaban versus short-term enoxaparin for the prevention of venous thromboembolism after total hip arthroplasty: a double-blind, randomised controlled trial. Lancet. 2008 ; 372 ( 9632 ): 31 - 39.

5. Dahl OE, Aspelin T, Arnesen H, Seljeflot I, Kierulf P, Ruyter $R$, Lyberg, T. Increased activation of coagulation and formation of late deep venous thrombosis following discontinuation of thromboprophylaxis after hip replacement surgery. Thromb Res 1995;80:299-306.

6. Wang CJ, Wang JW, Weng LH, Huang CC, Yu PC. Clinical Significance of Muscular Deep-vein Thrombosis after Total Knee Arthroplasty Chang Gung Med J 2007:30:41-6

7. Januel JM, Chen G, Ruffieux C, Quan H, Douketis JD, Crowther MA, Colin C, Ghali WA, Burnand B. IMECCHI Group. Symptomatic in-hospital deep vein thrombosis and pulmonary embolism following hip and knee arthroplasty among patients receiving recommended prophylaxis. JAMA 2012;307:294-303

8. Lieberman, JR, Hsu K. Prevention of venous thromboembolic disease after total hip and knee arthroplasty. J. Bone Joint Surg. Am. 2005; 87:2097-2112

9. Dixon J, Ahn E, Zhou L, Lim R, Simpson D, Merriman EG. Venous thromboembolism rates in patients undergoing major hip and knee joint surgery at Waitemata District Health Board: a retrospective audit. Intern Med J. 2015 Apr;45(4):416-22. doi: 10.1111/imj.12702.

10. Mann KG, Brummel K, Butenas S. What is all that thrombin for? J Thromb Haemost 2003;1:1504-14.
11. Husebye, EE, Opdahl H, Røise O, Aspelin T, Lyberg T. Coagulation, fibrinolysis and cytokine responses to intramedullary nailing of the femur: an experimental study in pigs comparing traditional reaming and reaming with a one-step reamer-irrigator-aspirator system. Injury2011; 42(7): 630-7. doi: 10.1016/j.injury.2010.06.025. Epub 2010 Jul 22

12. McNally MA, Mollan RA. Total hip replacement, lower limb blood flow and venous thrombogenesis. J Bone Joint Surg Br 1993;75:640-4.

13. Petrovic $D$. The role of vascular endothelial growth factor gene asthe genetic marker of atherothrombotic disorders and in the gene therapy ofcoronary artery disease. Cardiovasc. Hematol. Agents. Med. Chem.2010;Jan,8(1):47-54

14. Petrovic D, Milanez T, Kobal J, Bregar D, Potisk KP, Peterlin, B. Prothrombotic gene polymorphisms and atherothrombotic cerebral infarction. Acta Neurol. Scand. $2003 ; 108(2): 109-13$.

15. Geerts WH, Bergqvist D, Pineo GF, Heit JA, Samama CM, Lassen MR, Colwell CW. American College of Chest Physicians. Prevention of venous thromboembolism: American College of Chest Physicians evidence-based clinical practice guidelines (8th Edition). Chest 2008; 133; 381-453

16. Lützner DL, Kuhlisch WE. Hartmann A, Günther KP, Weiss, N, BeyerWestendorf, J. Efficacy and safety of venous thromboembolism prophylaxis with fondaparinux or low-molecular weight heparin in a large cohort of consecutive patients undergoing major orthopaedic surgery - findings from the ORTHO-TEP registry. $\mathrm{Br} \mathrm{J}$ Clin Pharmacol. 2012 Apr 20. doi: 10.1111/j.1365-2125.2012.04302.x.

17. Kang J, Jiang X, Wu B. Analysis of Risk Factors for Lower-limb Deep Venous Thrombosis in Old Patients after Knee Arthroplasty. Chin Med (engl). 2015; 28(10):1358-62. doi: 10.4103/0366-6999.156782.

18. Friedman RJ, Gallus AS, Cushner FD,Fitzgerald G, Anderson FAJr. Global Orthopaedic Registry Investigators.. Physician compliance with guidelines for deep-vein thrombosis prevention in total hip and knee arthroplasty. Curr Med Res Opin 2008;24:87-97.

19. Leclerc JR, Geerts WH, Desjardins L, Jobin F, Laroche F, Delorme F, Haviernick S, Atkinson S, Bourgouin J. Prevention of deep vein thrombosis after major knee surgery - a randomized, double-blind trial comparing a low molecular weight heparin fragment (enoxaparin) to placebo. Thromb Haemost. 1992 ;67 ( 4 ): 417 - 423.

20. Samama CM, Clergue F, Barre J, Montefiore A, III P, Samii, K. Arar Study Group. Low molecular weight heparin associated with spinal anaesthesia and gradual compression stockings in total hip replacement surgery. Br J Anaesth. 1997,;78 ( 6 ): 660 - 665.

21. Collins R, Scrimgeour A, Yusuf S, Peto R. Reduction in fatal pulmonary embolism and venous thrombosis by perioperative administration of subcutaneous heparin. Overview of results of randomized trials in general, orthopedic, and urologic surgery. N Engl J Med. 1988;318 ( 18 ): $1162-1173$

22. Francis CW, PellegriniVD Jr, Totterman S, Boyd AD Jr, Marder VJ, Liebert KM, Stulberg BN, Ayers, DC, Rosenberg A, Kessler C, Johanson NA. Prevention of deep-vein thrombosis after total hip arthroplasty. Comparison of warfarin and dalteparin. J Bone Joint Surg A $1997 ; 79$ ( 9 ): $1365-1372$.

23. Fitzgerald RH Jr, Spiro TE, Trowbridge AA, Boyd AD Jr, Marder VJ, Liebert KM, Stulberg BN, Ayers D, Rosenberg A, Kessler C, Johanson NA. Enoxaparin Clinical Trial Group. Prevention of venous thromboembolic disease following primary total knee arthroplasty. A randomized, multicenter, open-label, parallel-group comparison of enoxaparin and warfarin. J Bone Joint Surg Am. 2001; 83-A ( 6 ) : 900 - 906

24. Francis CW, PellegriniVD Jr, Totterman S, Boyd AD Jr, Marder VJ, Liebert KM, Stulberg BN, Ayers, DC, Rosenberg A, Kessler C, Johanson NA. Prevention of deep-vein thrombosis after total hip arthroplasty. Comparison of warfarin and dalteparin . J Bone Joint Surg A $1997 ; 79$ ( 9 ): $1365-1372$

25. Warkentin TE, Greinacher A, Koster A, Lincoff AM. Treatment and prevention of heparin induced thrombocytopenia. Chest 2008; 133:340-380

26. Lassen MR, Bauer KA, Eriksson BI, Turpie AG. European Pentasaccharide Elective Surgery Study (EPHESUS) Steering Committee. Postoperative fondaparinux versus preoperative enoxaparin for prevention of venous thromboembolism in elective hip-replacement surgery: a randomised doubleblind comparison. Lancet. 2002 ; 359 ( 9319 ):1715- 1720. 
27. Turpie, A.G.; Bauer, K.A. ;Eriksson, B.I ; Lassen, M.R. PENTATHALON 2000 Study Steering Committee. Postoperative fondaparinux versus postoperative enoxaparin for prevention of venous thromboembolism after elective hipreplacement surgery: a randomised double-blind trial. Lancet. 2002; 359 ( 9319 ): 1721 - 1726.

28. Comp, P.C.; Spiro, T.E.; Friedman, R.J.; Whitsett, T.L.; Johnson, G.J.; Gardiner, G.A Jr.; Landon, G.C.; Jové, M , Enoxaparin Clinical Trial Group. Prolonged enoxaparin therapy to prevent venous thromboembolism after primary hip or knee replacement. J Bone Joint Surg Am. 2001; 83-A ( 3 ): 336 - 345

29. 29. Dahl OE, Andreassen G, Aspelin T, Müller C, Mathiesen P. Nyhus S, Abdelnoor M, Solhaug JH, Arnesen H. Prolonged thromboprophylaxis following hip replacement surgery - results of a double-blind, prospective, randomised, placebo controlled study with dalteparin (Fragmin). Thromb Haemost. 1997;77 (1): 26 - 31.

30. Hull RD, Pineo GF, Francis C, Bergqvist D, Fellenius C, Soderberg K, Holmqvist A, Mant M, Dear R, Baylis B, Mah A, Brant R. North American Fragmin Trial Investigators. Low-molecular-weight heparin prophylaxis using dalteparin extended out-of-hospital vs in-hospital warfarin/out-of-hospital placebo in hip arthroplasty patients: a double-blind, randomized comparison. Arch Intern Med. 2000;160 ( 14 ): $2208-2215$.

31. Eriksson BI, Lassen, MR. Pentasaccharide iH-FSPI. Duration of prophylaxis against venous thromboembolism with fondaparinux after hip fracture surgery: a multicenter, randomized, placebo controlled, double-blind study. Arch Intern Med 2003;163(11), :133742.

32. Turpie AG, Bauer KA, Eriksson BL, Lassen MR. Fondaparinux vs enoxaparin for the prevention of venous thromboembolism in major orthopedic surgery: a meta-analysis of 4 randomized double-blind studies. Arch Intern Med 2002;162:1833-1840

33. Heit JA, Lahr BD, Petterson TM, Bailey KR, Ashrani AA, Melton LJ3rd. Heparin and warfarin anticoagulation intensity as predictors of recurrence after deep vein thrombosis or pulmonary embolism: a population-based cohort study. Blood. 2011; Nov 3 118(18) : 4992-9.

34. Nutescu EA. Bautista A, Gao W, Galanter WL, Schumock GT, Mody SH, Bookhart BK, Lambert BL. Warfarin anticoagulation after total hip or total knee replacement: clinical and resource-utilization outcomes in a university-based antithrombosis clinic. Am J Health Syst Pharm. 2013 Mar 1;70(5):423-30

35. Prandoni P, Bruchi O. Sabbion P, Tanduo C, Scudeller A, Sardella C, Errigo G, Pietrobelli F, Maso G, Girolami A. Prolonged thromboprophylaxis with oral anticoagulants after total hip arthroplasty: a prospective controlled randomized study. Arch Intern Med 2002;162:1966-71

36. McBride JA, Turpie AG, Kraus V, Hilz, C. Proceedings: failure of aspirin and dipyridamole to influence the incidence of leg scan detected venous thrombosis after elective hip surgery. Thromb Diath Haemorrh. 1975 ;34 ( 2 ): 564.

37. McKenna R, Galante J. Bachmann F, Wallace DL, Kaushal PS, Meredith, P. Prevention of venous thromboembolism after total knee replacement by high-dose aspirin or intermittent calf and thigh compression. BMJ. 1980;280 ( 6213 ): 514 - 517.

38. Raphael IJ, Tischler EH, Huang R, Rothman RH, Hozack WJ, Parvizi, J. Aspirin: An Alternative for Pulmonary Embolism Prophylaxis After Arthroplasty? Clin Orthop Relat Res. 2013 Jul 2. Epub ahead of print.

39. Jiang Y, Du H, Liu J, Zhou Y. Aspirin combined with mechanical measures to prevent venous thromboembolism after total knee arthroplasty: a randomized controlled trial. Chin Med J (Engl). 2014;127(12):2201-5.

40. Stangier J, Eriksson BI, Dahl OE. Ahnfelt L, Nehmiz G, Stähle $H$, Rathgen K, Svärd R. Pharmacokinetic profile of the oral direct thrombin inhibitor dabigatran etexilate in healthy volunteers and patients undergoing total hip replacement. J Clin Pharmacol 2005; 45:555-563.

41. Eriksson BI, Dahl OE, Rosencher N, Kurth AA, van Dijk C.N. Frostick SP, Prins MH, Hettiarachchi R, Hantel S, Schnee J, Büller HR . Oral dabigatran etexilate vs. subcutaneous enoxaparin for the prevention of venous thromboembolism after total knee replacement: the REMODEL randomized trial. J Thromb Haemost 2007;5:2178-2185

42. RE-MOBILIZE Writing Committee Oral thrombin inhibitor dabigatran etexilate versus North American enoxaparin regimen for prevention of venous thromboembolism after knee arthroplasty surgery. J Arthroplasty $2009 ; 24: 1-9$.
43. Lassen MR, Ageno W, Borris, L.C.; Lieberman, J.R.; Rosencher N.; Bandel, T.J.; Misselwitz, F.; Turpie, A.G. RECORD3 Investigators. Rivaroxaban versus enoxaparin for thromboprophylaxis after total knee arthroplasty. N Engl J Med. 2008 ;358 ( 26 ): 2776 - 2786.

44. Turpie AG, Lassen MR, Davidson BL, Bauer KA, Gent M, Kwong LM, Cushner FD, Lotke PA. Berkowitz SD, Bandel TJ, Benson A, Misselwitz F , FisherW.D. RECORD4 Investigators. Rivaroxaban versus enoxaparin for thromboprophylaxisprophylaxis after total knee arthroplasty (RECORD4): a randomised trial. Lancet. 2009 ;373 ( 9676 ): $1673-1680$.

45. Dahl OE, Quinlan DJ, Bergqvist D, Eikelboom JW. A critical appraisal of bleeding events reported in venous thromboembolism prevention trials of patients undergoing hip and knee arthroplasty. J Thromb Haemost. 2010; 8 ( 9 ): 1966 - 1975.

46. Jiang L, Zhang S, Zhao Y. Stacked Modalities' Thromboprophylactic Therapy for Patients Undergoing Total Knee Replacement Surgery. J Knee Surg. 2016 May 23. Epub ahead of print.

47. Lassen MR, Raskob GE, Gallus A, Pineo G, Chen D, Portman RJ. Apixaban or enoxaparin forthromboprophylaxis after knee replacement. N Engl J Med 2009,;361:594-604

48. Lassen MR, Raskob GE, Gallus A Pineo G, Chen D, Hornick P Apixaban versus enoxaparin forthromboprophylaxis after knee replacement (ADVANCE-2): a randomised double-blind trial. Lancet 2010; 375:807-15

49. Fuji T, Wang CJ, Fujita S, Kawai Y, Nakamura M, Kimura T, Ibusuki K, Ushida H, Abe K, Tachibana S.Safety and efficacy of edoxaban, an oral factor Xa inhibitor, versus enoxaparin for thromboprophylaxis after total knee arthroplasty: the STARS E-3 trial.Thromb Res. 2014 Dec;134(6):1198-204. doi: 10.1016/j.thromres.2014.09.011. Epub 2014 Sep 21

50. Sasaki H, Ishida K, Shibanuma N, Tei K, Tateishi H, Toda A, Yamashiro Y, Matsumoto T, Kuroda R, Kurosaka M Retrospective comparison of three thromboprophylaxis agents, edoxaban, fondaparinux, and enoxaparin, for preventing venous thromboembolism in total knee arthroplasty. Int Orthop. 2014 Mar;38(3):525-9. doi: 10.1007/s00264013-2132-x. Epub 2013 Oct 8.

51. Sakai T, Izumi M, Kumagai K, Kidera K, Yamaguchi T, Asahara T, Kozuru H, Jiuchi Y, Mawatari M, Osaki M, Motokawa S, Migita K.Effects of a Foot Pump on the Incidence of Deep Vein Thrombosis After Total Knee Arthroplasty in Patients Given Edoxaban: A Randomized Controlled Study. Medicine (Baltimore). 2016 Jan;95(1):e2247. doi: 10.1097/MD.0000000000002247

52. Sodha NR, Sellke FW.Reversal of Dabigatran with Idarucizumab Expert Rev Cardiovasc Ther. 2016 Jun 30:1-5. Epub ahead of print.

53. Yogaratnam D, Ditch K, Medeiros K, Doyno C, Fong JJ. Idarucizamab for Reversak of Dabigtran.Ann Pharmacother. 2016 Jul 7. pii 1060028016659504. Epub ahead of print. Review.

54. Papakostidis C, Harwood PJ, Karadimas EJ. Tan HB, Giannoudis PV The timing of drug administration for thromboprophylaxis following orthopaedic surgery: evidence and controversies related to treatment initiation and duration. Curr Vasc Pharmacol. 2011; 9(1):11-8

55. Zou Y, Tian S, Wang Y, Sun K Administering aspirin, rivaroxaban and low-molecular-weight heparin to prevent deep venous thrombosis after total knee arthroplasty..Blood Coagul Fibrinolysis. 2014 Oct;25(7):660-4. doi: 10.1097/MBC.0000000000000121.

56. Bern MM, Hazel D, Deeran E, Richmond JR, Ward DM, Spitz DJ, Mattingly DA, Bono JV, Berezin RH, Hou L, Miley GB, Bierbaum BE. Low dose compared to variable dose Warfarin and to Fondaparinux as prophylaxis for thromboembolism after elective hip or knee replacement surgery; a randomized, prospective study. Thromb J. 2015 Oct 7; 13:32. doi: 10.1186/s12959-015-0062-0. eCollection 2015.

57. Aryal MR, Pandit A, Ghimire S, Pathak R, Karmacharya P, Poudel DR, Shamoun FE. Thromboprophylaxis with apixaban and the risk of pulmonary embolism in patients undergoing knee replacement surgery. J Community Hosp Intern Med Perspect. 2015 Sep 1;5(4):27889. doi: 10.3402/jchimp.v5.27889.

58. Roosendaal G, Van Der Berg HM, Lafeber FPJG, Bijilsma JWJ. Chapter 3: Blood induced joint damage: an overview of musculoskeletal research in Haemophilia. In: Rodriguez-Merchan EC, 60. Goddard NJ, Lee CA eds. Muscoloskeletal Aspects of Haemophilia. Cambridge: Blackwell Science Ltd, 2000: 18-26.

59. Carulli C, Civinini R, Martini C, Linari S, Morfini M, Tani M, Innocenti M. Viscosupplementation in haemophilic arthropathy: a long-term follow-up study. Haemophilia 2012;18:e210-4 
60. Carulli C, Matassi F, Civinini R, Morfini M, Tani M, Innocenti M. Intra-articular injections of hyaluronic acid induce positive clinical effects in knees of patients affected by haemophilic arthropathy. Knee 2013;20:36-9.

61. Rodriguez-Merchan EC. Total knee replacement in haemophilic arthropathy. J Bone Joint Surg Br 2007;89:186-8.

62. Takedani H, Ohnuma K, Hirose J. Deep venous thrombosis was not detected after total knee arthroplasty in Japanese patients with haemophilia. Haemophilia 2015;21:585-588.

63. Carulli C, Felici I, Martini C, Civinini R, Linari S, Castaman G, Innocenti M. Total hip arthroplasty in haemophilic patients with modern cementless implants. J Arthroplasty 2015; 30:1757-60.

64. Valentino LA, Cooper DL, Goldstein B. Surgical experience with rFVlla (NovoSeven) in congenital haemophilia $A$ and $B$ patients with inhibitors to factors VIII or IX. Haemophilia 2011;17:579-89.

65. Caviglia H, Candela M, Galastro G, Neme D, Moretti N, Bianco RP. Elective orthopaedic surgery for haemophilia patients with inhibitors: single centre experience of 40 procedures and review of the literature. Haemophilia 2011;17:910-9.

66. Escobar M, Maahs J, Hellman E. Multidisciplinary management of patients with haemophilia with inhibitors undergoing surgery in the United States: perspectives and best practices derived from experienced treatment centres. Haemophilia 2012;18:971-981.

67. Falck-Ytter Y, FrancisC.W, Johanson N.A, Curley C, Dahl O.E, Schulman S, Ortel TL, Pauker SG, Colwell CW Jr. Prevention of VTE in Orthopedic Surgery Patients Antithrombotic Therapy and Prevention of Thrombosis, 9th ed: American College of Chest Physicians Evidence-Based Clinical Practice Guidelines Chest 2012; 141 (2) (Suppl): e278S-e325S

68. Guideline on Prevention of Symptomatic Pulmonary Embolism in Patients Undergoing Total Hip or Knee Arthroplasty. Adopted by the American Academy of Orthopedic Surgeons Board of Directors May 2007. Available at:www.aaos.org/research/guidelines/PE_guideline. pdf. Accessed December 17, 2008.

(C) SAGEYA. This is an open access article licensed under the terms of the Creative Commons Attribution Non-Commercial License (http://creativecommons.org/licenses/by-nc/3.0/) which permits unrestricted, noncommercial use, distribution and reproduction in any medium, provided the work is properly cited.

Source of Support: Nil, Conflict of Interest: None declared 